\title{
A Simulation of Entrepreneurial Spawning
}

\author{
Mark J. O. Bagley ${ }^{1}$ \\ ${ }^{1}$ International Business School, Jönköping University, Gjuterigatan 5, Jönköping, 551 11, Sweden \\ Correspondence should be addressed to mark.bagley@ju.se \\ Journal of Artificial Societies and Social Simulation 20(3) 9, 2017 \\ Doi: 10.18564/jasss.3444 Url: http://jasss.soc.surrey.ac.uk/20/3/9.html \\ Received: 01-07-2016 Accepted: 23-03-2017 Published: 30-06-2017
}

\begin{abstract}
This paper describes how patterns of industrial clustering arise with respect to the size of an initial firm when measured in terms of innovation. Through principles of evolutionary economics, the aim of this paper is to examine the 'birth' of industrial clusters. We take an endogenous and supply-side approach, where firms in a region spawn from incumbents. Technology is qualitatively described using a code set mapped on a cognitive space. Assuming inheritability of networking skills, we seek to model how the size of an initial firm influences future patterns of cluster formation through a model of technical cognition and a mimicking of creativity. It is found that initial firm size has a lasting impact on clustering patterns through its influence on the level of cognitive distance of the underlying agents. The model replicates the stylised facts of entrepreneurial cluster formation.
\end{abstract}

Keywords: Industrial Clusters, Spin-Offs, Schumpeter, Evolutionary Economic Geography, Technological Change

\section{Introduction}

1.1 The traditional paradigm of agglomeration economies expanding on Marshall (1920) and Jacobs (1969) focusses on firms choosing to move or locate alongside similar businesses to benefit from knowledge spillovers, specialized infrastructure and economies of scale. However, more recent models have taken an evolutionary approach to analyzing industrial cluster formation. Specifically, industrial clusters arise as a result of spin-offs from incumbent firms. The geographic clustering of firms of similar industry as a result of entrepreneurial spawning is a well-documented phenomenon. Klepper (2011) sums up three empirical regularities that link entrepreneurial spawning with industrial clusters. First, there is a performance premium of spin-offs starting in the same industry as the parent firm. Entrepreneurs 'inherit' the knowledge and routines of their former workplaces and deploy these attributes to the newly established firm. Second, there is a premium for locating a spin-off in the same region as the parent firm. Entrepreneurs have little incentive to relocate to a new area when they have already established geographically-bounded networks and ties. Finally, the birth of industrial clusters coincides with new technologies and the evolutionary branching of a given industry.

1.2 This paper will adhere to these concepts of inheritance and evolutionary branching and will describe how existing industry structure in a region conditions spawning patterns using a highly-simplified model of technical cognition. To understand the birth of clusters, we seek to explore what role industry structure plays in cluster formation. If industrial clustering patterns are indeed a result of entrepreneurial spawning, then the specific patterns of industrial clusters could arise from the characteristics of the entrepreneurs themselves, which in turn may arise from the industrial environments they have been exposed to. Firms of different sizes require different skill sets; the resources needed to run a large firm are not necessarily the same as those of a smaller firm. Furthermore, different sized firms may attract different types of workers; more 'ambitious' workers may wish to seek employment with a larger firm given the long-term promotion prospects they offer. Conversely, smaller firms offer a narrower industrial focus and potentially provide experience with small, newly established firms.

1.3 Empirical studies have examined the link between spin-offs ${ }^{1}$ and their parent firms. Smaller firms tend to spawn more often, however these spin-offs tend to be of lesser quality when measured in profitability or size. Likewise, larger firms tend to spawn less frequently, but spin-offs tend to be of higher quality ${ }^{2}$. Past studies have found 
a variety of factors that have an impact on this pattern, namely; disagreements between the innovator and the firm, imperfect information on innovative employees, product scope and focus, and self-selection. What remains is whether spin-off patterns can be explained by market structure, the amount of knowledge, and networking. Can we explain clustering behaviour as a product of cognition of various actors? This paper adheres to the view that industrial clusters are a result of the level of technical cognition within the system, and this level of cognition is a function of the initial condition, i.e. the initial size of the de novo firm.

1.4 Frenken \& Boschma (2007) expand on previous studies of path dependence Simon (1955); David (1985); Arthur (1989) by viewing economic development as an evolutionary branching process of product innovations, while overcoming the problematic issues of using spatial entities as the unit of analysis. The unit of analysis is instead the firm, and the existing variety within firms and cities provide the scope of innovation that leads to an evolutionary process of economic growth. A set of probabilistic organizational parameters describe the branching process which in turn is a product of incremental and radical innovations. The parameters measure the likelihood that an entrepreneur will cultivate a new idea in her current firm, an alternative firm, or as a new firm in the form of a spin-off. Given a firm and city of a certain size, organizational parameters adjust through a system of positive and negative feedback loops. As first modelled by Simon (1955, the organizational parameters produce a Zipf's law for both the firm and city size distribution. According to a set of exogenous factors, assumptions of entrepreneurial motivations and actions lead to an explanation of clustering patterns, and these actions in turn contribute to the evolution of future entrepreneurial decisions.

1.5 This paper will extend Frenken \& Boschma 2007) model by using ideas and knowledge as the unit of analysis. By adhering to the simplicity of Frenken \& Boschma 2007) model, we contextualize the presence of specific resources, which is knowledge and ideas. By doing so, we address the aforementioned assumptions by modelling spin-offs as a manifestation of knowledge and ideas, shaped at the firm level. We may therefore consider how industrial conditions influence the branching process of product innovations.

1.6 We employ an abstract computational model that allows us to model concepts (in this case knowledge and ideas) that are somewhat immeasurable in the real world. The context of analysis is not employees, inventors or entrepreneurs. Rather, such entities act as vectors that conceptualize knowledge and ideas through Schumpeterian motivations. Knowledge and ideas are unique and are the primary focus and means of measurement in this paper. Each firm in the system carries one or more of these ideas that can be represented within what is called a cognitive space (explained below). We use the presumption that new ideas are a function of existing ideas. These ideas interact with each other and combine to form new ideas. The ability for one idea to interact with another is bounded by its cognitive reach, which in turn is a function of the size of a firm's parent firm at the time of spin-off. Furthermore, a new idea may lead to the spawning of a new spin-off firm if such an idea fails to fit in within the old firm's existing knowledge set. Due to series of factors, a firm's knowledge set (which expands as a firm grows) is often a function of the size of the firm's parent firm. Finally, we also assume that an entrepreneur has knowledge of her parent firm's idea set. We use stylised facts of spin-off patterns as a guideline for model validation.

1.7 Thus, while defining smaller firms as having a smaller knowledge set, such firms are less likely to grow as they have fewer existing ideas to combine. However, if a smaller firm originated as a spin-off from a large firm, this may not be the case. Such spin-offs may inherit the networking abilities of the parent firm as well as utilizing the parent firm's knowledge set. The founders of such small firms, who typically originate from senior management from the parent firm, facilitate these characteristics. Firms also inherit long-term growth strategies through this manner. Thus, initial market structure has a path-dependent impact on the pattern of industrial spawning.

1.8 In the following section, we provide a framework that links firms, entrepreneurs and knowledge, thereby exploring the differences of how incremental and radical innovations arise. We then introduce the model by transferring these concepts to a formal model by introducing the cognitive space and how firms and entrepreneurs, acting as vectors for knowledge and ideas, behave within this space. As a test for validation, we then compare the results of this simulation to the stylised facts of entrepreneurial spawning patterns with respect to the size of the incumbent firm. Finally, we use the model's results as an explanation behind Zipf's law, that is, the constraints of a firm's own knowledge lead to the rank-size distribution of firms observed in the real world. The ultimate section concludes. 


\section{A Model of Entrepreneurial Spawning}

\section{Firms, entrepreneurs, and knowledge}

2.1 The relationship between firms and their subsequent spin-offs reflects the characteristics of the firms themselves ${ }^{3}$. Klepper \& Sleeper 2005 use the notion that parent firms "give birth" to spin-offs, who in turn inherit a set of traits. In this case these traits may be thought of as knowledge and ideas. In a sense, it is the qualities of a parent that is of relevance to the study of spin-offs. Spin-offs inherit knowledge of their parents' product focus and production routines. However, although offspring do take many of their attributes from their parents, they do have certain characteristics that differentiate them from their predecessors. To use an evolutionary analogy, the increasing fitness of a species is not only the result of the combinations and recombinations of genetic material, but also a function of new genetic identities in the form of mutations.

2.2 An assumption of the model in this paper is that these spin-offs are a result of the "Schumpeterian entrepreneur", a rare and radical idea generator who in turn opens a new market landscape. Provided the radical idea is perceived to be profitable (either directly or indirectly), the entrepreneur will leave her firm and establish a new one. Thus, a computational model is useful when analysing industrial clusters as it considers the heterogeneous nature of the initial conditions of market structure. New firms spawn from existing firms when agents happen upon an idea that is perceived as innovative, and this perception of innovativeness is a function of both the profoundness and quality of the new idea. Furthermore, this measure of perception is a function of the actors' existing knowledge set, which is bounded by the entrepreneur's own exposure to ideas already present in her own Weltanschauung, or world-view, which is in turn bounded by her position in the cognitive field. New ideas are therefore products of old ones, a pattern often seen. Take, for example, the printing press, which did not arise out of 'thin air' but was instead a combination of existing technologies, catalysed by the skill of the inventor. The basic mechanism of the printing press was taken from the existing wine press and the development of oil-based ink. Gutenberg, who had a background as a goldsmith, improved upon existing type-setting technologies while combining these existing technologies. The mechanization of paper manufacture as well as the switch from scrolls to codex provided the motivation of invention. The printing press in turn eased the spread of ideas, leading to the enlightenment, which in turn led to the birth of further new ideas and so on ${ }^{4}$.

2.3 Thus, the innovation potential of a firm is bound by the firm's internal and external knowledge set. Antonelli 2010, p. 165), expanding on work by Patrucco 2009, maintains that firms must rely on knowledge exploration strategies to innovate in the long-term, and "only when a firm is able to fully coordinate learning and research activities conducted within its boundaries with the relevant sources of external knowledge, both tacit and codified, can new knowledge be successfully generated". However, not all firms are bound by the same knowledge-search curve. Spin-offs traditionally arise from an entrepreneur with a history of experience and/or senior management in another firm (Andersson \& Klepper 2013. Klepper \& Sleeper 2005). One can assume that such individuals have varying levels of expertise of firm coordination and product knowledge, as well as contrasting sizes of networks and networking ability. This variation in expertise is a function of the entrepreneur's employment history. Entrepreneurs originating from larger firms tend to have larger networks (especially with her former firm), a greater knowledge set of ideas, and grander aspirations of future firm size.

2.4 A new idea, if radical enough, could in turn lead to the formation of a new firm; due in part to the entrepreneur's perception of future profits, as well as the failure for the new idea's ability to fit into the parent firm's existing routine and cognitive set. In the context of this model, therefore, new firms are a product of the 'Schumpeterian entrepreneur', a rare and radical idea generator:

"It is the entrepreneur who carries out new combinations, who leads the means of production into new channels" ... "He also leads in a sense that he draws other producers in his branch after him. But as they are his competitors, who first reduce and then annihilate his profit, this is, as it were, leadership against one's own will" (Schumpeter 1934, p. 89)

2.5 Dahlman et al. (1987), Kim (1980) and Lall (1992) outline the sensitivity of local conditions, in terms of the availability of knowledge, on future development possibilities. The current model captures these effects by means of setting up these local conditions as the model's initial environment. A region with one large firm as an initial condition will thus lead to a market structure radically different to one that begins with many small firms, given the heterogeneous and heuristic nature of the actors as outlined above. 


\section{The cognitive space}

2.6 Real-world analysis is limited due to an immeasurable world. Solé et al. (2014) discuss the difficulties in studying technological change due to the lack of a genome mapping for various designs, as well as the complex nature of how these designs evolved and came into being. Given the level of abstraction in this model, a computational simulation presents a suitable choice as qualitative concepts can be difficult to measure. Thus, we introduce a measurable artificial world that serves as a proxy to understand real-world behaviour. This artificial world is the cognitive space, a concept we use to understand the different spawning patterns of small and large firms. To use the definition by Nooteboom et al. (2007. p. 1017), "Cognition denotes a broad range of mental activity, including proprioception, perception, sense making, categorization, inference, value judgements, emotions, and feelings, which all build upon each other". In the context of this paper, the cognitive space encapsulates this definition by providing a measurable playing ground for actors within the model.

2.7 A summary of the concepts defined in this section may be found in Table 1 . We start the model by assuming one city-sized geographic area, where all firms locate. This eliminates the need to consider geographic proximity in the model, and to focus on cognitive aspects alone. Consider a piece of knowledge, idea or technology, which in this paper will be captured as a $k \mathrm{n}^{5}$. A ken is an abstract concept that may be interpreted as 'an element of knowledge'. Although technologies may be represented as a ken (or a combination of kens), not all kens are necessarily technologies. This ken comprises of several characteristics that give the ken its purpose. These characteristics add up to express a ken's phenotype ${ }^{6}$, or its set of observable traits. To simplify, assume that all kens lie in a three-dimensional vector-space, i.e. the cognitive space of the system. The phenotype of ken i may be expressed as:

$$
k_{i}=\left(p_{1 i}, p_{2 i}, p_{3 i}\right), k_{i} \in D, D \subseteq \mathbb{R}^{3}
$$

where $p_{1 i}, p_{2 i}$ and $p_{3 i} \hat{a} A \mathrm{AL}^{\prime}$ combine to represent the phenotype of ken $k_{i}$, which lies in the cognitive space ${ }^{7} D$. Here, $p_{1 i}, p_{2 i}$ and $p_{3 i}$ are coordinates in the three-dimensional cognitive space. This allows for a measure for which kens qualitatively differ from one another. Thus, the cognitive space coincides with a technological one. Figure 1 illustrates this in terms of a two-dimensional context.

2.8 The cognitive space is infinite, meaning that there is an unlimited number of phenotypes possible. The cognitive distance, $D_{i j}$ of a pair of kens $i$ and $j$ is the cognition, $D$, between them and measured in a Euclidian manner. We may view the cognitive distance as the relatedness of two kens, $\mathrm{i}$ and $\mathrm{j}$, interpreted by a set of heuristic players, which may include firms and individuals. In Figure 1, with three kens $k_{a}, k_{b}$ and $k_{c} ; D_{a b}<D_{a c}$. Therefore, $k_{a}$ and $k_{c}$ are more 'related' to each other, in a cognitive sense, than $k_{a}$ and $k_{b}$. Nooteboom et al. (2007, p. 1017) interprets cognitive distance as a shared 'interpretation system' where "labor needs to share certain basic perceptions and values to sufficiently align their competencies and motives". In this case, cognitive distance measures the difference between two specific kens, and firms and individuals serve as the vectors for those kens.

2.9 Whereas the cognitive distance simply measures the level of cognition between two kens, this does not tell us their ability to 'interact'. The emergence of a new ken originates with the interaction of two existing kens, facilitated by the innovative behaviour of firms. This interaction is governed by the cognitive reach of that actor, $R_{i}$, or the actor's potential 'vision' of ideas and concepts ${ }^{8}$. The specific cognitive reach of each actor in period $t$ is imposed by a general Gompertz probability distribution with a shape parameter of 1 and a scale parameter $r$ :

$$
R_{i t} \sim f(r ; D)=r e^{r D} e^{1-e^{r D}}
$$

2.10 Thus, the probability ${ }^{9}$ of an interaction between kens $i$ and $j$ depends on $r$. The Gompertz distribution is chosen as it allows for a certain degree of comparatively high cognitive reach up until a certain point, until which it drops off to lower levels of probability ${ }^{10}$. With higher levels of $r$, the Gompertz distribution becomes 'squeezed' and therefore potential cognitive reach becomes limited to closer kens. Thus, increasing and decreasing $r$ leads to a lower and higher cognitive reach. We assume that actors have a generally good knowledge of similar ideas, but this knowledge falls off dramatically after a certain point. Therefore, two kens may interact if the following condition is satisfied:

$$
R_{i t} \geq D_{i j}
$$

2.11 Thus, the cognitive reach of one ken must be greater than or equal to the cognitive distance of the pair. Time in the model is measured in discrete units. In each time period, all kens establish a cognitive reach according to Equation 2 and, if meeting the condition in Equation 3, establishes a link with one other ken only. Thus, 


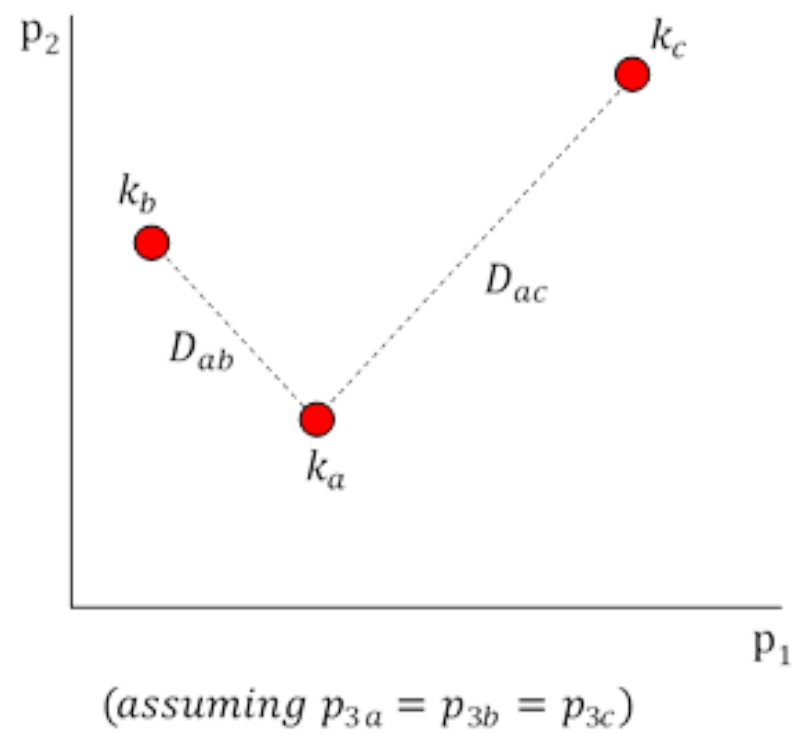

Figure 1: The Cognitive Space

\begin{tabular}{ll}
\hline Concept & Definition \\
\hline Cognitive space & $\begin{array}{l}\text { A three-dimensional vector space. Each vector, which one may picture as three axes of } \\
\text { a graph, measures one of the three elements of phenotype }\left(p_{1}, p_{2}, p_{3}\right) .\end{array}$ \\
Ken & $\begin{array}{l}\text { 'An element of knowledge'. Takes on three unique phenotypes, }\left(p_{1 i}, p_{2 i}, p_{3 i}\right) \text {, measured } \\
\text { in the cognitive space. }\end{array}$ \\
Cognitive distance & $\begin{array}{l}\text { The measured cognition between two kens } i \text { and } j . \text { In terms of the cognitive space, } \\
\text { this is the Euclidean distance between } i \text { and } j(\text { see Figure } 1 . \text { Thus, if ken } i \text { had the } \\
\text { phenotype }\left(p_{1 i}, p_{2 i}, p_{3 i}\right) \text {, and ken } j \text { had the phenotype }\left(p_{1 j}, p_{2 j}, p_{3 j}\right) \text {, then the cognitive } \\
\text { distance between the two would be: } D_{i j}=\left[\left(p_{1 i}-p_{1 j}\right)^{2}+\left(p_{2 i}-p_{2 j}\right)^{2}+\left(p_{3 i}-p_{3 j}\right)^{2}\right]^{1 / 2}\end{array}$ \\
& $\begin{array}{l}\text { An actor's potential 'vision' of ideas and concepts. In the context of the model, this } \\
\text { Cognitive reach }\end{array}$ \\
& $\begin{array}{l}\text { 'vision' pertains to a given ken, and its ability to search the cognitive space around it. } \\
\text { If a ken 'finds' another ken within this search radius, those two kens may interact. }\end{array}$ \\
\hline
\end{tabular}

Table 1: Summary of key concepts

outgoing links are limited to a maximum of one per ken. The number of incoming links per ken, however, is potentially infinite.

2.12 Upon the interaction of two kens, a third ken generates through both a crossover and mutation process. The mutation may be understood as the level of creativity employed during the birth of the third ken. For simplicity as well as to conserve computing power, a crossover (which in a biological framework is simply the recombination of two phenotypes) is the halfway point of two kens. The mutation, which is the deviation from the point of crossover, is a function of the cognitive distance of the two. The mutation process may be seen in Figure 2. Mutation may be thought of as an accident, or a spurt of creativity.

2.13 The new ken is 'born' and the specific point is a random distance with a probability imposed by a Gompertz distribution with a scale parameter $D_{i j}$, as seen in Figure 2 and Equation 4

$$
m \sim f\left(D_{i j} ; D\right)=D_{i j} e^{D_{i j} D} e^{1-e^{D_{i j} D}}
$$

We put forward this constraint as any further deviation outside this limit would entail a level of creativity that is outside the influence of the two kens that influence that level.

Rule No. 1: If two kens, $i$ and $j$, interact, a third ken is born, and the specific location of the third ken is dictated by a Gompertz distribution with a scale parameter $D_{i j}$. 


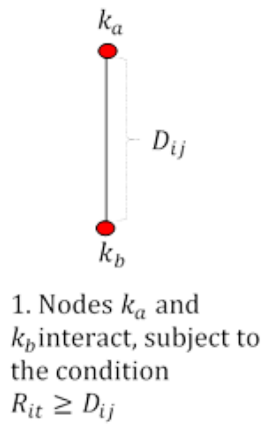

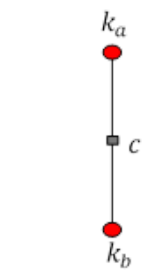

2. A crossover point, marked a $c$ forms half way between $k_{a}$ and $k_{b}$.

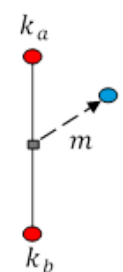

3. A new node forms, where $m$ is a mutation

from its crossover point.

Figure 2: The Crossover and Mutation Process

\section{System behaviour}

2.14 Schumpeter 1934, p. 65) describes the underlying mechanics of economic growth as "The spontaneous and discontinuous changes in the channel of the circular flow... the producer who as a rule initiates economic change, and consumers are educated by him if necessary. They are, as it were, taught to want new things, or things which differ in some respect or other from those which they have been in the habit of using. . To produce other things, or the same thing by a different method, means to combine these materials and forces differently". There are five cases Schumpeter 1934) identifies where recombination occurs. This includes the introduction of a new good, the introduction of a new method of production, the opening of a new market, the conquest of a new source of supply or raw material and the carrying out of a reorganization of an industry.

2.15 Nooteboom et al. (2007) details the relationship between cognitive distance and innovation performance; as cognitive distance increases, there is an increase in learning by interaction. A 'stimulus' occurs when people with different knowledge sets interact, which in turn consolidates previously diverse knowledge. This only occurs up to a certain point, however. When cognitive distance reaches a certain point, there is an insufficient level of mutual understanding. The relationship between cognitive distance and innovation performance is therefore U-shaped. Actors, seeking to maximize their innovative potential, must therefore find concepts that are sufficiently new to them, but not so new as to limit their understanding ${ }^{11}$.

2.16 Arthur 2005) adds to this assertion that new technologies arise from a Darwinian process, which itself is a process of variation of existing technologies and their subsequent improvement. Furthermore, new technologies are combinations of old ones, even if these new technologies bear little resemblance to the ones they derived from. This is a natural condition. Schumpeter (1934) stresses that any new combination must draw the necessary means of production from old combinations. Furthermore Arthur 2005) cites the example of the turbojet, which was a combination of the magnetron (high power output) and the klystron tube, which are both aspects of two very different purposes. Although a solution is sometimes found by systematically seeking out various possibilities, the usual route is often unsystematic and the discovery is accidental. Returning to the example of the printing press, Koestler (1964) points out that Gutenberg, in the process of seeking the ideal mechanism, first turned to traditional methods he was familiar with, such as printing from wood blocks by means of rubbing and methods for coin-casting, both proving insufficient for means of mass-producing the written word. To solve this problem, Gutenberg had to turn to an entirely different kind of skill. He discovered this by chance, by taking part in a wine harvest. The wine press was used as the eventual element for the invention of the printing press.

2.17 The current model does not make any explicit distinction between incremental and radical innovation. Radical innovation has been defined as something that disrupts or redefines a performance or trajectory Christensen \& Bower 1996), a "radical exploration [that] builds upon distant technology that resides outside the firm", (Rosenkopf \& Nerkar[2001, p. 290) or something that "serve[s] as the basis of 'future' technologies, products and services" (Ahuja \& Morris Lampert|2001, p. 522). Building upon these viewpoints, this paper defines a radical innovation as the result of a new ken that is considerably different from the existing technology set. Radical innovation is implicit, an indirectly observable change that causes further changes in the system. Although it is more than possible to define a concrete definition or distinction within the model, such a distinction would be ambiguous as radical innovation takes on a range of unbounded and continuous values. For the purpose of understanding this model, therefore, only an implicit distinction is made.

2.18 The model starts with an initial technology set, which is defined as $n_{0}$. The value of $n_{0}$ is the only exogenously 


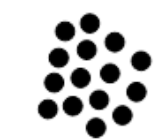

1. The initial technology set.

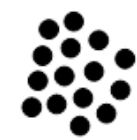

2. A relatively extreme mutation produces a radical innovation.

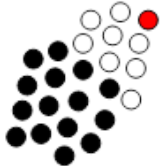

3. Incremental innovations fill the gap between the radical innovation and the existing technology set.

Figure 3: System Behaviour.

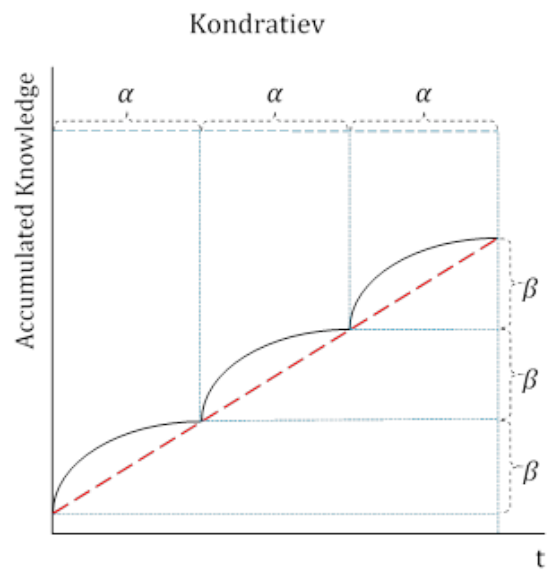

Kondratiev and Schumpeter

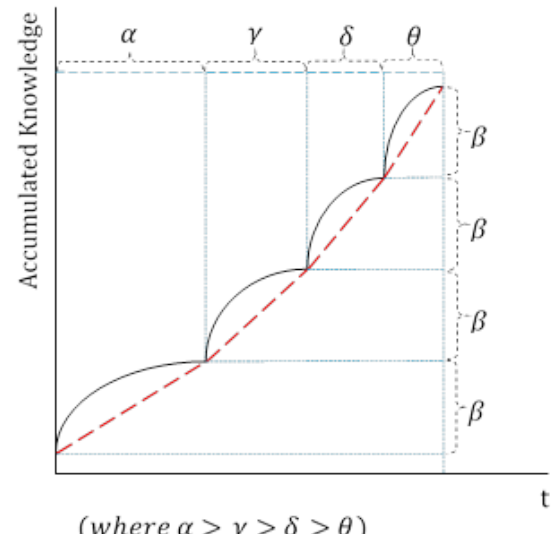

Figure 4: Kondratiev and Schumpeterian Growth Curves ${ }^{13}$.

adjustable parameter in the simulation (the other being global distribution of cognitive reach, dependent on $r$ ). Time is discrete, and within each unit of time actors act to produce the next value of $n_{t}$. As discussed, any two kens may interact if $R_{i t} \geq D_{i j}$. A new ken is generated only if that ken occupies a previously unoccupied section of the cognitive space. Although the cognitive space is continuous in nature, this is to account for the lack of value of a ken that is too similar to the existing technology set. Thus:

Rule No. 2: All kens must be unique to a part of the cognitive space. This part has an area equal to one.

2.19 Furthermore, there is no measure for the relative quality of new kens, nor is there a fitness landscape. All ideas are 'good kens' and worth pursuing. Figure 3 illustrates the system's behaviour. Given an initial technology set, a radical innovation is born through the interaction of two kens with a relatively large cognitive distance, an extreme mutation, or both, seen in step two. We may consider this ken a radical innovation as its position in the cognitive space is relatively far away from the existing technology set. In time, interaction with the invention born in step two produces a consolidation of the technology set, which are kens that emerge in-between the invention and the rest of the kens. The more radical an innovation, the greater the potential growth of future technology, via means of incremental innovation. The overall effect is a rapid yet temporary increase in the number of kens because of the radical innovation. We may consider the new kens in step three as incremental innovations as they are new to the system but not 'radical' in the sense that they are already bounded by an existing technology set. The system then enters a steady state until a new radical innovation occurs.

2.20 The result of this behaviour is an S-shaped growth curve, as seen in Figure 4. For illustrative purposes, take for example Kondratiev waves ${ }^{12}$ on the left-hand side of the figure. Radical kens take place at the 'dips', or inflection points. After this point, spurts of innovation fill the gap that was created by that radical ken. Eventually, this rate of growth levels off when further incremental ken creation consolidates the gap between the new invention and the original technology set. A new spurt of innovation occurs when there is another eventual radical innovation. This process continues until perpetuity. 


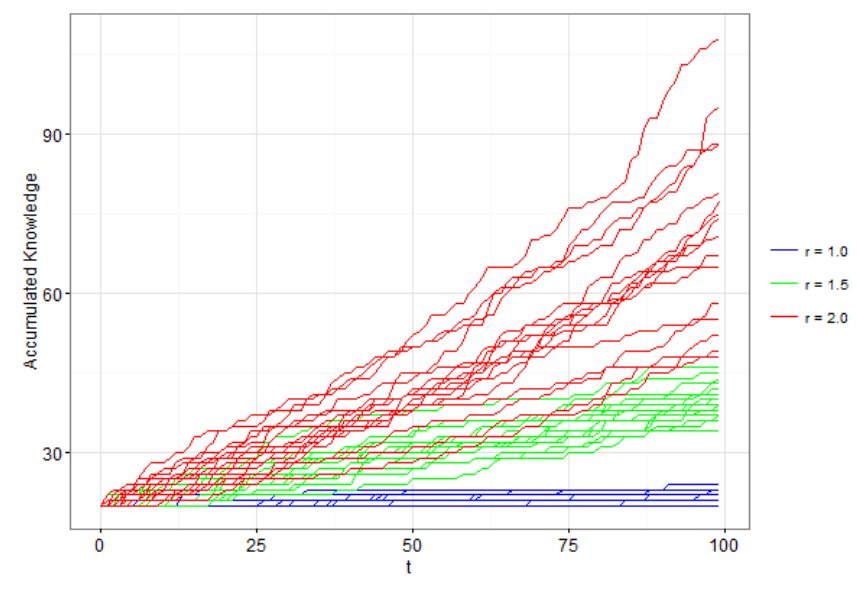

Figure 5: Rates of technological growth with different levels of $r$.

2.21 Schumpeter 1943, p. 83) expanded on these Kondratiev waves by introducing 'creative destruction', or the "[revolution] of economic structure from within, incessantly destroying the old one, incessantly creating a new one". Furthermore, each wave becomes steeper than the last due to the acceleration of technological advancements. Figure 4 illustrates this. The heights of each successive wave in both the Kondratiev and Schumpeter growth curves are equal, denoted by a value of $\beta$. However, as each wave in the Kondratiev growth curve is of equal wavelength (measured by $\alpha$ ), in the Schumpeter growth curve, wavelengths successively decrease (with each four measured by relative magnitudes $\alpha, \gamma, \delta$, and $\theta$, with $\alpha>\gamma>\delta>\theta$ ). A red dotted line traces the inflection points of both growth curves. In the case of Schumpeter (on the right-hand side), this produces a nonlinear line with an exponential nature. This is in contrast with the Kondratiev (on the left-hand side) with each wavelength being equal to $\alpha$ (producing a linear and straight red dotted line).

2.22 Figure 5 illustrates this behaviour by simulating the model at three different values for $1 / r ; 1.0,1.5$ and 2.0. The simulation is run 10 times for each of these three parameters. All three give the same S-shaped behaviour of technological growth. The increasing rate of growth is a result of the ever-increasing horizon of the technology set. New kens, and especially radical ones, are born most often on the periphery. If this periphery becomes ever-larger, because of the increased number of existing kens on that periphery, the number of potential new kens in the next time period increases. The inflection points of these curves (and thus the probability of invention), however, are less frequent with smaller levels of $1 / r$. As the cognitive reach of kens increase, so does the technology set's growth potential. Increasing $1 / r$ further will eventually lead to a 'super-Malthusian' growth rate, or a finite-time singularity described by Solé et al. (2014). Increasing the potential cognitive reach of kens through $1 / r$ therefore accelerates the advancement of knowledge. Furthermore, the variance of the accumulation of knowledge increases at higher levels of $1 / r$. Lower levels of $1 / r$ (such as when it is set to 1.0) often fail to produce significant knowledge growth. Biggiero \& Valente (2016) using Kauffman's 1993 1996: 2000) NK model, also reach this conclusion, i.e. a lack of initial knowledge heterogeneity (which may be also understood as quantity in the current model) hinders knowledge growth in industrial clusters.

2.23 This model does not consider the redundancy of old technology, as it is generally assumed that the kens of redundant technology is ever-present and drawn upon by future kens. As time goes on, older kens have less use as a factor for new kens as they become confined deeper into the interior. New combinations make old ones redundant only in the sense that older technologies are not used as frequently as the new.

2.24 The technological growth rates in Figure 5 is largely consistent with our understanding of how ideas evolve. Arts \& Veugelers 2014 expands on anecdotal evidence and use patent data to study innovation in biotechnology. For each patented invention, they were able to identify the search process of previous patents that led to the invention's design. It was found that new technologies were a result of recombining and revising familiar technologies. However, recombining more familiar technologies typically do not produce novel breakthroughs. Bigger breakthroughs require a deeper technological understanding. The exponential nature of technological growth is due to the ever-increasing periphery of the stock of kens.

\section{Spin-off conditions}

2.25 Spin-offs in this model are multi-generational, i.e. a spin-off in one time period may serve as a parent firm in a later time period. The decision to spin-off is a function of the entrepreneur's own knowledge set of kens, which 
may come from her own firm or others. The entrepreneur's knowledge set, which varies from entrepreneur to entrepreneur, limits her perceived degree of ingenuity of a new idea. Of course, this is a simplification, as one may discover ideas in organizations that are not firms (e.g. family, friends, unions, clubs, etc.). People tend to belong to multiple types of organization at the same time. Indeed, multiple membership is arguably an important property of social systems; allowing ideas, competencies and skills to transcend (Biggiero 2001). This paper, however, does not reject the idea of multiple membership of many types of organization ${ }^{14}$, although the model does not deal with it explicitly. Actors draw on at least one ken from their own organization. We use 'firms' to simplify our discussion. This does not imply that the vectors of ideas do not belong to other types of organization, and it also does not imply that they only seek out new combinations of knowledge directly from other firms. They may arrive at this point via other channels. What the model shows is simply how cognitively proximate two kens are.

2.26 A number of empirical studies examine the entrepreneur's decision to leave an incumbent firm and establish a spin-off. Hvide 2009) used Norwegian data to analyse a model of interaction between the decision to become an entrepreneur and the employer's motivation to keep the best ideas with the firm. Because larger firms have less information regarding employee quality, wages become less flexible. Therefore, higher quality workers are more likely to leave the firm and establish a start-up. Garvin (1983) refers to employees leaving parent firms out of a result of becoming frustrated with their employers. However, this frustration is due to an idea being rejected. Klepper (2007), found that there was evidence with this frustration in the automotive industry as management tends to be constrained in recognizing employees with higher talent. Tenure, as well as perceived opportunities for future promotion may also have a negative impact on spin-off frequency Andersson \& Klepper 2013). Tåg et al. (2013) and Elfenbein et al. (2010) found evidence that the decreased amount of hierarchy (measured in terms of the number of layers of management) in smaller firms contributes to the increased level of entrepreneurial spawning. This is presumably due to the increased perception of future opportunities and promotion and their accompanying financial incentives. However, Tåg et al. (2013) were only able to account for one-fifth of entrepreneurial spawning as a result of increased bureaucracy. Other studies focus on firm-level events to explain the frequency of spin-off rates. Brittain \& Freeman (1986) argue that in the semiconductor industry, firms that were acquired by non-semiconductor firms or those that hired a CEO from outside of the firm were more likely to spawn new firms. Klepper \& Sleeper 2005), in their study of the laser industry, found that the probability of firm spawning was related not only to the parent firm's total experience in producing lasers, but also to the parent's focus of producing a particular type laser, and not its general experience. Thus, spinoffs were a seen to be a function of not only their parents' total knowledge of laser production, but also their targeted knowledge. Brittain \& Freeman 1986 assume that firms that do not have a primary focus often rotate their employees across different business sectors, which in turn limits their access to the industrial knowledge needed by a prospective entrepreneur. There may also be a self-sorting mechanism with regard to larger firms; ambitious individuals may have a tendency to choose bigger firms at the start of their careers.

2.27 The remaining question concerns how the distribution of knowledge and ideas is linked to the spin-off decision of the entrepreneur. The aforementioned empirical studies rely on observable characteristics of the incumbent firm in relation to the entrepreneur. The next step is to link these observations and apply it to the branching process of product innovation as outlined by Frenken \& Boschma (2007). Up until this point we have built a model that addresses the dynamics of technological growth. Now let us use this framework to address firmlevel behaviour and the decision to spin-off. We design this part of the model to take into account the empirical observations discussed above. Equation 2 defined the cognitive reach between two kens. This was conditional on a pre-set condition defined as $r$, the scale parameter of the Gompertz probability distribution. We can expand on this by making $r$ an endogenous condition, determined by the size of a firm. Thus:

$$
\frac{1}{r}= \begin{cases}\log _{10} \frac{n_{0}}{a}, & \text { for the first firm, } a>1 \\ \log _{10} L_{p}, & \text { for all subsequent firms (at time of spinoff) }\end{cases}
$$

2.28 Where $L_{p}$ is the size of the parent firm and $a$ is an exogenously given constant ${ }^{15}$ greater than one. This inheritance process assumes that those in control of a new firm inherit the cognitive scope or 'vision' of the firm she was employed at previously. If this firm is large, the larger cognitive reach of that larger firm reflects the need to 'know' about the greater variety of various designs, processes and routines. Smaller firms (if they are de novo) have a naturally smaller $1 / r$ due to the lack of need, i.e. a smaller scope or 'vision' is required for the management of a smaller quantity of kens. Furthermore, a spin-off takes a value of $1 / r$ that is a function of the size of her parent firm. This is because the entrepreneur brings with her the routines and skills that are applicable for the parent firm. This was verified by Agarwal et al. (2004), who found that an incumbent's capabilities at the time of spin-off positively affect the entrant's knowledge capabilities. 


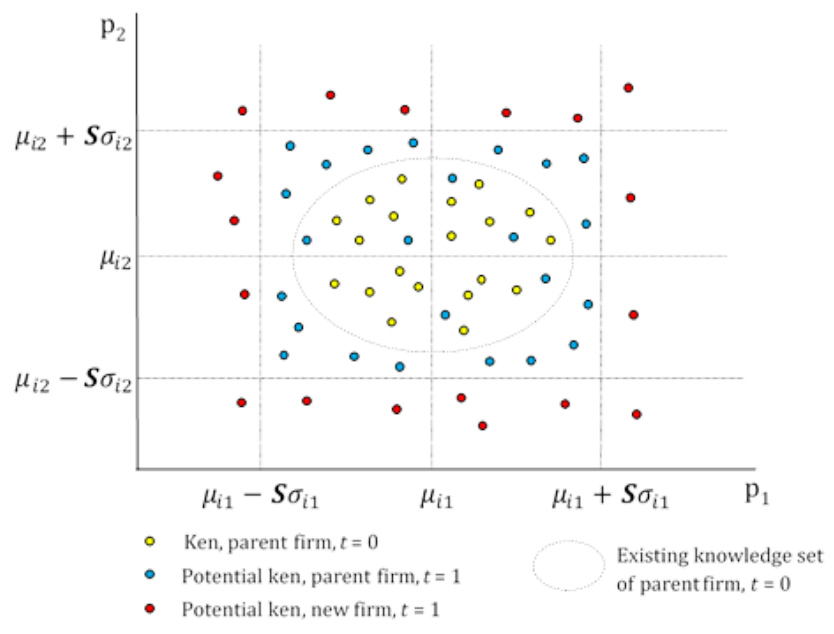

Figure 6: The Schumpeterian Condition ${ }^{16}$.

Rule No. 3: All firms have a value of $r$ that is a function of the size of their parent firms, at the time of spin-off.

2.29 One condition governs the possibility of a new ken leading to an entrepreneurial spin-off; the Schumpeterian condition. This condition must hold true for a spin-off to occur. As shown in Figure 6 , the Schumpeterian condition describes how radical a new ken must be to spawn as a new firm. This condition is satisfied for a new ken with the phenotype $\left\{p_{k 1}, p_{k 2}, p_{k 3}\right\}$ by:

$$
p_{k w} \geq \mu_{i w}+S \sigma_{i w}, w=1,2,3
$$

where, for the parent firm of ken $i, \sigma_{i w}$ is the standard deviations of $p_{i 1}, p_{i 2}$ and $p_{i 3}$; and $\mu_{i w}$ the respective means. The Schumpeterian multiplier, $S$, dictates how extreme a new ken needs to be to be considered as an 'outlier' of the parent firm's existing knowledge set. The relative threshold for spin-offs differs from firm-tofirm, and depends not only on $S$ but also the scope, focus and size of the parent firm when measured in terms of number of kens, captured by the standard deviational ellipse in Equation 6

2.30 Furthermore, the spin-off also inherits the Schumpeterian multiplier from the parent firm, which is again dependent on the size of the parent firm (measured in kens). Formally:

$$
S= \begin{cases}\log _{10} n_{0}, & \text { for the first firm } \\ \log _{10} L_{p}, & \text { for all subsequent firms (at time of spinoff) }\end{cases}
$$

2.31 The Schumpeterian multiplier may also be thought of as the degree to which new ideas fit in to the existing firm. Following from Cassiman \& Ueda (2006), exceeding this multiplier is effectively an incentive for an entrepreneur to leave the parent firm and establish a start-up. This is the degree to which an entrepreneur views a new idea as radical. The entrepreneur, the parent firm, or both, may have a 'sense' of this multiplier. These are passed down from firm-to-firm as an entrepreneur, if her firm is not de novo, is assumed to come with the experience of managing a large firm. A de novo small firm would have a smaller Schumpeterian multiplier as the management required would need to only be adept at managing a smaller scope. The relationship between de novo firm size and its future potential for growth is transformative; the larger the firm, the standard deviational ellipse of that firm increases disproportionally. However, given that spin-offs (and specifically, the founders of spin-offs) inherit a sense of scope from their parent firm, the Schumpeterian multiplier carries through as a function of the size of the parent firm at the time of spin-off, just as in the case of $r^{17}$.

Rule No. 4: All firms 'inherit' $S$ that is a function of the size of their parent firms.

2.32 So far, kens interact per their cognitive reach as shown in Equation 2. However, interaction is not limited to this property. It is also assumed that a firm, if it is a spin-off firm, may also be able to interact with kens belonging to its parent firm (illustrated in Figure 7), and with equal probability ${ }^{18}$. An entrepreneur is assumed to have a good level of knowledge about the products and processes of the firm she was employed at previously. This 


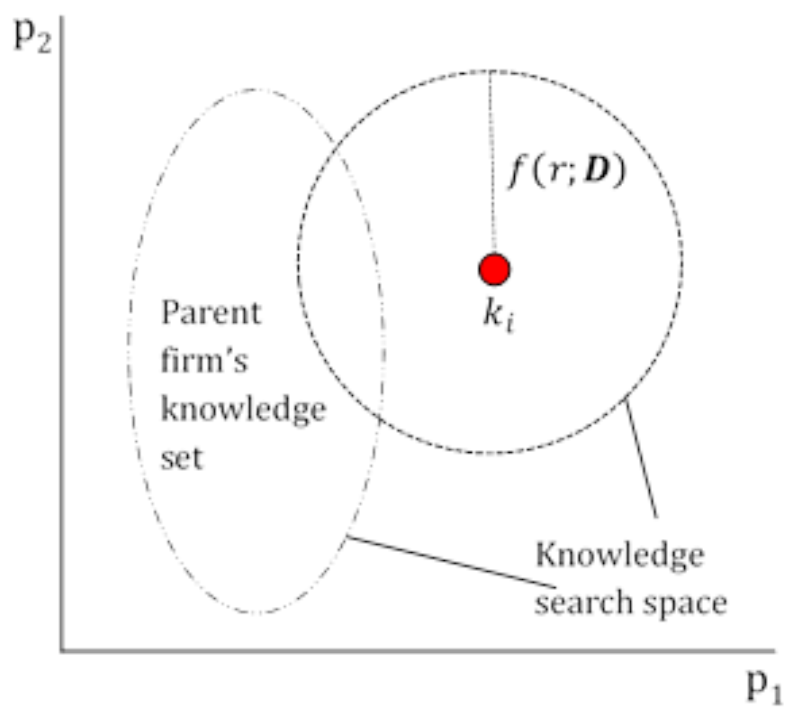

Figure 7: Knowledge search space.

follows from Klepper 2010) in that hereditary issues may lead to clustering of firms. Furthermore, we take the view that larger firms require unique skills for coordination efforts, and this transpires into a higher networking ability of the entrepreneur, as well as an increased search space.

Rule No. 5: In addition to their own cognitive reach, a ken's knowledge search space also includes the parent firm's knowledge set ${ }^{19}$.

2.33 We may also interpret spin-off behaviour (encapsulated by the Schumpeterian multiplier) from the perspective of Henderson \& Clark (1990), who define two types of knowledge: component knowledge and architectural knowledge. While the former concerns the 'pieces' of a technology, the latter is how these pieces are put together. Incremental innovations, which are much more common, involve the advancement of component knowledge. This is due to two principles: the 'dominant design' of a technology and the restriction of a firm's information channels to that dominant design ${ }^{20}$. Once an industry accepts a dominant design, information channels within the firm adhere to it, producing a 'lock-in' of evolution of a given product group. Established firms tend to limit themselves to improvements in component knowledge due to these information channel restrictions. Advancements in architectural knowledge, on the other hand, produce radical breakthroughs. These prisons of information flow do not restrict newly established firms and are therefore free from making a costly transition to new system of thinking, and enjoy a relative tabula rasa in cognition, routines and processes.

2.34 A summary of the model may be seen in Figure 8 . The simulation outlined above takes into account concepts of inheritance, interaction (bound by cognitive constraints), as well as a spawning process when new firms arise. The spawning process itself has its own constraints that are brought about through earlier mechanisms. What results is a system where past firm size (measured in terms of kens) influences the present and future size of a firm via a path dependent process. To summarise, one sets up the simulation by first setting the size of the initial firm, $n_{0}$, measured in kens (which in turn attain $1 / r$ and $S$ per Equations 5 and 7 ). The simulation then begins its first time period, with kens interacting with one another according to Equations 2 and 3 New kens then come into existence via a crossover and mutation process as shown in Equation 4 and Figure 2. Then, new firms may or may not come into being as stated in Equation 6. Depending again on Equations 5 and 7 , new kens attain their scale parameters and Schumpeterian multipliers. This marks the end of the time period, after which the process starts again with the interaction phase in the second time period. This 'loop' continues indefinitely or for a stipulated number of time periods predefined by the user of the simulation.

2.35 A snapshot of the simulation may be seen in Figure $9^{1}$. Spin-offs often occur on the periphery of the parent firm's existing knowledge set. This may or may not hinder the future growth performance of the parent firm, as it depends entirely on the parent firm's attributes, i.e. its cognitive reach, Schumpeterian multiplier and current size. In this framework, firms do not 'fail'. In many cases, however, when spawning does occur, older firms may have a growth rate that approaches zero due to multiple spin-offs forming on the periphery of the parent firm's knowledge set, which can effectively 'crowd out' growth of the parent firm. Indeed, this has been 


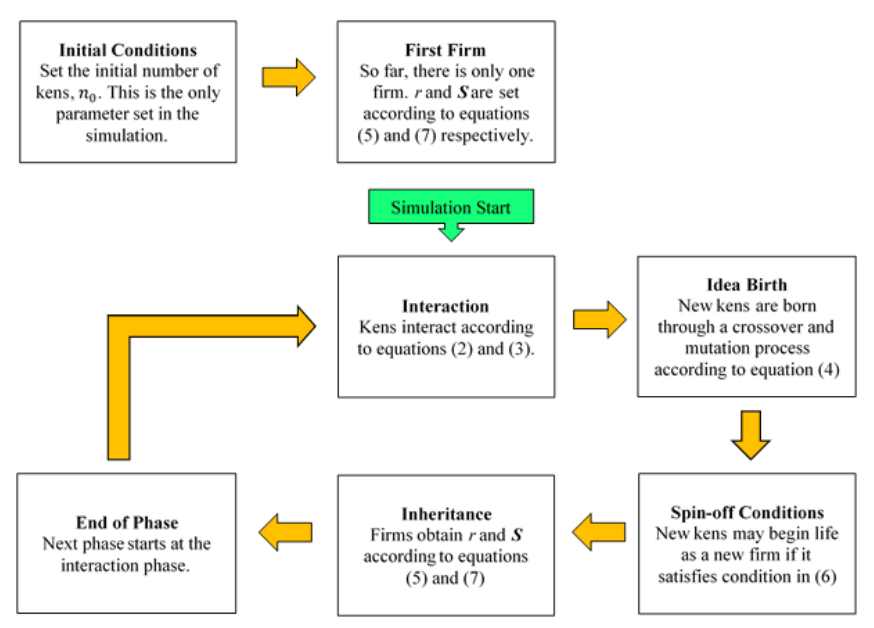

Figure 8: Simulation overview.

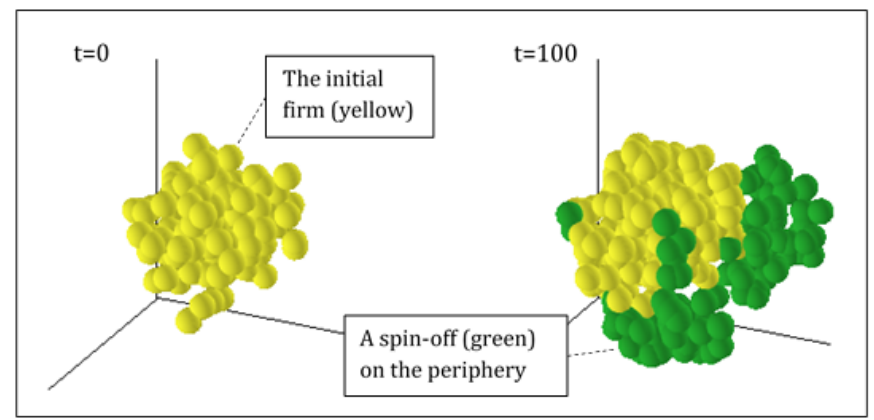

Figure 9: A simulation snapshot.

shown empirically (McKendrick et al.|2009: Phillips 2002). Furthermore, we exclude the possibility of mergers and takeovers, and analyse firms only in their own right from the time of spin-off.

\section{Results and Discussion}

3.1 The simulation models the firm as an entity of knowledge. We propose that it is knowledge that is both the enabler and constraint of firm growth. To illustrate this, we bridge the gap between the simulation and the findings of empirical work by comparing the model to stylised facts. The purpose of this is two-fold. First, this acts as a verifier to the simulation. Second, this gives the simulation, which in itself is based on a highly abstract view of knowledge and cognition, some degree of explanatory power behind spin-off patterns by taking into account qualities that are difficult to measure in the real world. Table 2 summarizes these stylised facts, along with the simulation's results.

3.2 Within the simulation, the growth curves of individual firms typically display an initial spurt of growth followed by a levelling off to a rate of zero. The presence of other firms exacerbates the limits of firm growth, which, if bordering the periphery, are likely spawns of the declining firm.

3.3 Therefore, it is common to observe that the majority of spawning occurs toward the beginning of a simulation, before the initial incumbent firm is at a size that erodes the possibility of new firms. Klepper \& Sleeper (2005), in their study of the laser industry, found that spin-offs were more likely at the middle-age of the parent firm. In the simulation, firms exist into perpetuity, so there is no real definition of a firm's 'middle-age'. The initial firm is exogenously given, with no indication of its age. However, Klepper \& Sleeper (2005) propose that a change in the kind of information generated affects spawning times, which in turn compromises the knowledge available for employees to exploit. The first spawn, if any, usually occurs during the early stages of the simulation. The exogenously set constant, a, is responsible for this pattern. The larger the size of the initial firm, the later in the simulation the first spawn occurs. This may be seen in Figure 10, which plots three runs. In this simulation, the 


\begin{tabular}{|c|c|}
\hline Stylised Fact & Result \\
\hline $\begin{array}{l}\text { Number of spawns } \\
\text { When measured per employee, larger firms tend to } \\
\text { spawn less frequently, while smaller firms spawn } \\
\text { more frequently |Gompers et al. 2005; Sørensen } \\
\text { 2007;: Elfenbein et al. 2010; Wagner|2004: Eriksson \& } \\
\text { Kuhn|2006: Klepper 2009). }\end{array}$ & $\begin{array}{l}\text { When measured per ken, we obtain a negative rela- } \\
\text { tionship between initial firm size and the number of } \\
\text { spin-offs (Figure } 11 \text {. }\end{array}$ \\
\hline $\begin{array}{l}\text { Quality of spawns } \\
\text { When measured in terms of performance, larger } \\
\text { firms tend to spawn firms of higher quality, while } \\
\text { smaller firms spawn firms of lesser quality (Anders- } \\
\text { son \& Klepper|2013 |Hvide|2009||Klepper|2009: Chris- } \\
\text { tensen|1993| Franco \& Filson 2000). }\end{array}$ & $\begin{array}{l}\text { When measured in terms of kens, the size of the ini- } \\
\text { tial firm provides a constraint on the size of any po- } \\
\text { tential future firm (Figure } 12 \text {. }\end{array}$ \\
\hline $\begin{array}{l}\text { Zipt's law } \\
\text { Irrespective of how one defines firm size, the rank- } \\
\text { size distribution of firms follows a Zipf distribution } \\
\text { with a coefficient close or equal to one (Axtell|2001; } \\
\text { Stanley et al.|1996| Amaral et al.|1997.|1998). }\end{array}$ & $\begin{array}{l}\text { All simulations lead to a Zipf distribution irrespective } \\
\text { of initial firm size. Zipf's law is observed for a unique } \\
\text { and consecutive subset of } n_{0} \text { parameters (Table } 3 \text {. }\end{array}$ \\
\hline
\end{tabular}

Table 2: Summary of key concepts

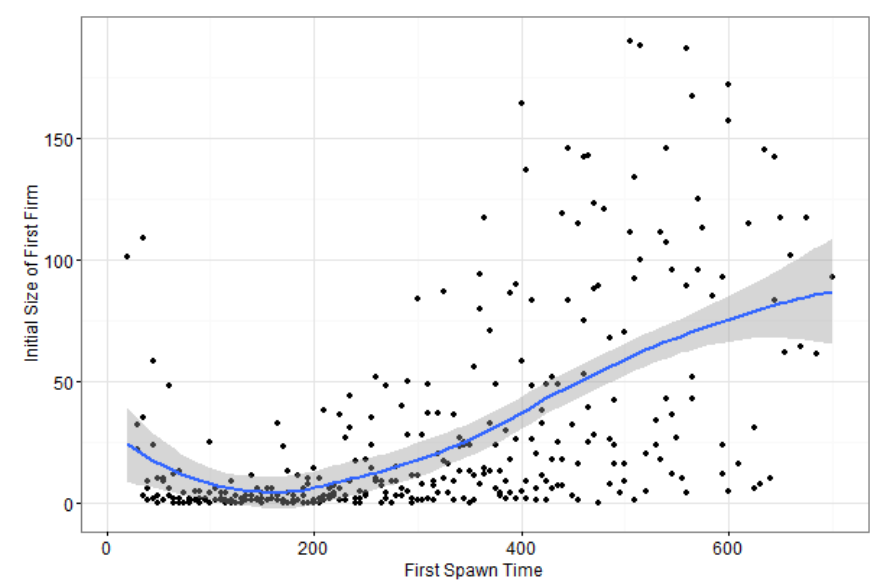

Figure 10: First spawn times.

model is run for 200 time periods.

3.4 Andersson \& Klepper (2013) and Hvide (2009) found that the higher the quality of entrepreneurs leaving larger firms, the better performance of the spin-off founded by those outgoing employees. This is comparable to the findings in earlier work by Burton et al. (2002); Christensen (1993); Franco \& Filson 2000). Furthermore, Gompers et al. (2005) found that although the largest companies spawn the most new firms, when measured in terms of annual spawning per million of employees it is actually the smaller firms that were more likely to spawn new firms. This was also confirmed by Sørensen (2007); Elfenbein et al. (2010); Wagner (2004); Eriksson \& Kuhn 2006). Klepper (2009) found that, when measured by longevity, peak market share, early entry, and product quality and scope; better performing firms have higher rates of entrepreneurial spawning. When measured in terms of the number of spin-offs per employee, the rate of entrepreneurial spawning is higher for smaller firms. Gompers et al. (2005) found that firms that had an employment range of 100 employees or less (the lowest category) displayed a considerably higher rate of entrepreneurial spawning, at least four times that of any other category. Thus, the more likely incubators for entrepreneurs may well be that of other small, entrepreneurial firms, a setting where employees acquire the knowledge and skills needed to start a new establishment. All of these studies use variables that are largely observable. The model predicts spawning patterns according these stylised facts, and these may be seen in Figure 11, which illustrates the number of firms at $t=200$ with respect to the size of the initial firm, as well as the size of each firm with respect to the initial size of the initial firm (in Figure 12]. This builds upon the aforementioned empirical studies (Andersson \& Klepper 2013: Hvide 2009; Gompers et al. 2005 , etc.) by taking into account the nature of innovation, i.e. new technology being a function 


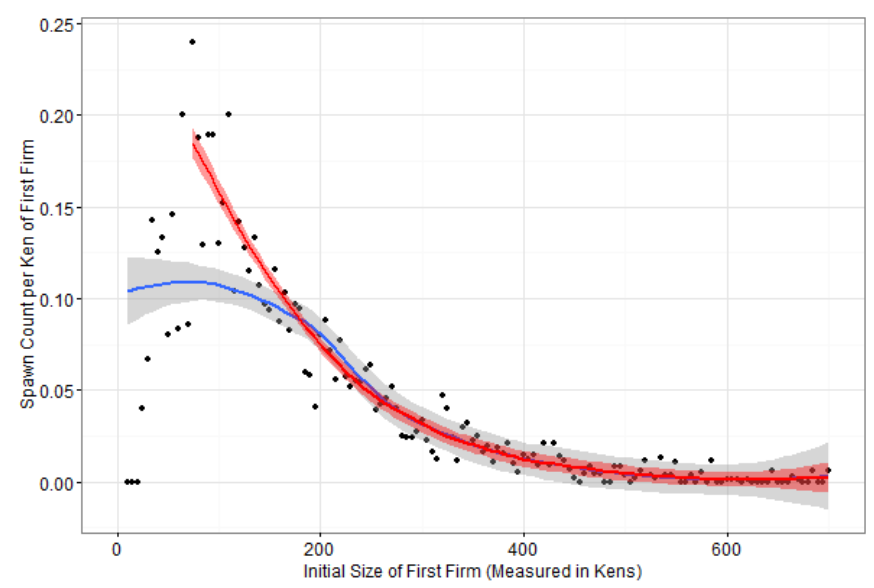

Figure 11: Number of spawns at $t=200$.

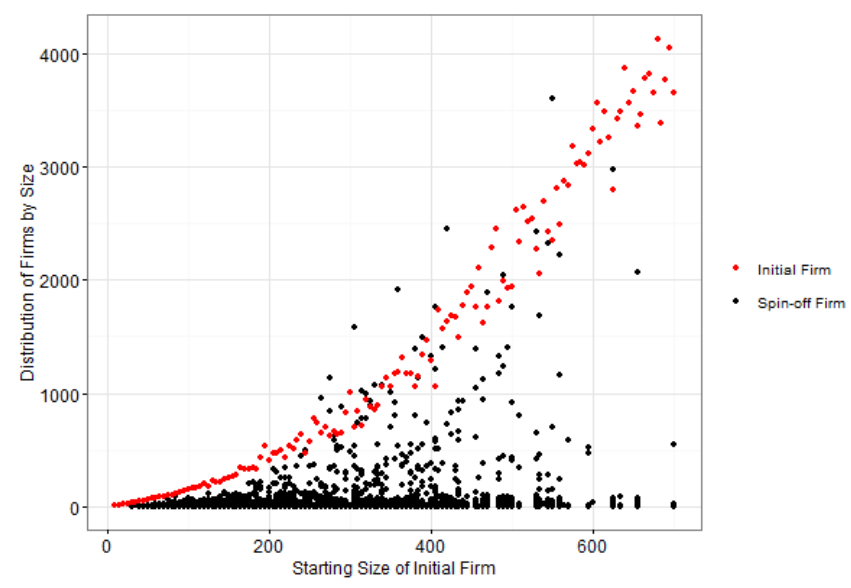

Figure 12: Size distribution of firms at $t=200$.

of old ones. One firm, with an initially large size, will produce few firms, but these firms are large and similar in size to the original. A small firm will often lead to many smaller ones.

3.5 With very large firm sizes, the likelihood of a spin-off diminishes with a 'monopoly effect'; the initial firm, along with its Schumpeterian multiplier, becomes too large to make spawning behaviour likely as the firm internalizes all innovation. For very small firms, that is, with a technology set of less than 30 , spin-offs are also less likely due to the cognitive reach of kens being too small to produce any new kens. The overall trend is one that is sub-exponential, but with greater variation as initial firm size increases. The variation is due to the presence of other firms, and the exponential shape is a result of the Schumpeterian growth of the entire system as illustrated earlier in Figures 4 and 5 .

3.6 As seen in Figure 11, the number of spawns per ken falls as the size of the parent firm increases. Two overlaid fitted polynomial predicted lines illustrate this relationship; a blue fitted line (which considers all observations) and a red fitted line (which excludes the first 13 observations). The blue fitted line reflects a relatively low cognitive reach with respect to the Schumpeterian multiplier for small initial firm sizes. After that threshold, the reverse is true. Spin-off frequency is therefore a function of the relationship between $r$ and the Schumpeterian multiplier. The red line illustrates this post-threshold relationship. Aghion et al. (2005) found a similar relationship with respect to competition and innovation. At very low and very high levels of product market competition, innovation is constrained, whereas at intermediate levels a Schumpeterian effect dominates. Figure 12 plots the final size of all spin-offs (marked in black) at the end of the simulation, compared to the final size of the initial firm (marked in red). Final spin-off size, measured in kens, roughly follows the final size of the initial firm. Hence, this replicates the stylized facts of previous empirical studies (Andersson \& Klepper 2013; Hvide 2009; Klepper 2009; Christensen 1993, Franco \& Filson 2000, that show that higher quality firms tend to spawn higher quality spin-offs.

3.7 A final stylised fact is the size distribution of firms obeying Zipf's law. Several authors Axtell|2001. Stanley et al. 


\begin{tabular}{cccc}
\hline Initial firm size & $\beta$ & $\chi^{2}(1)$ & Number of firms \\
\hline$n_{0}=50$ & $1.18664(0.0601)$ & $9.66^{*}$ & 50 \\
$n_{0}=60$ & $1.2300(0.0547)$ & $17.65^{*}$ & 55 \\
$n_{0}=70$ & $1.0901(0.0363)$ & $7.64^{*}$ & 100 \\
$n_{0}=75$ & $1.0440(0.0363)$ & $1.47^{\dagger}$ & 103 \\
$n_{0}=80$ & $1.0198(0.0288)$ & $0.47^{\dagger}$ & 107 \\
$n_{0}=85$ & $0.9629(0.0269)$ & $1.91^{\dagger}$ & 134 \\
$n_{0}=90$ & $0.9595(0.0246)$ & $2.72^{\dagger}$ & 171 \\
$n_{0}=95$ & $1.0064(0.0220)$ & $0.08^{\dagger}$ & 166 \\
$n_{0}=100$ & $1.0783(0.0217)$ & $13.08^{*}$ & 155 \\
$n_{0}=150$ & $1.0317(0.0158)$ & $4.02^{*}$ & 279 \\
$n_{0}=300$ & $1.3262(0.1084)$ & $905.07^{*}$ & 218 \\
$n_{0}=450$ & $1.6596(0.0137)$ & $2331.01^{*}$ & 97 \\
\hline
\end{tabular}

All coefficients significant at the $1 \%$ level

* Reject at the $10 \%$ level of significance.

Exhibits Zipf's law.

Table 3: Maximum Likelihood Estimates for the Zipf Distribution

1996. Amaral et al. 1997, 1998) observe that when plotting the log of the firm's size against its rank ${ }^{22}$, the outcome is a linear distribution with a slope close to one. In other words, the $n^{\text {th }}$ largest firm is $1 / n$ the size of the largest firm. This distribution is unaffected by mergers and acquisitions, firm entry and exit, as well as largescale demographic transitions and technological change (Axtell 2001). To test this observation on our simulation results, we perform a maximum likelihood (ML) estimation to fit a Zipf distribution, which may be seen in Table 3, which shows the estimates obtained at varying levels of $n_{0}$. Irrespective of the setting, we obtain a Zipf distribution with statistically significant ML estimates. Zipf's law, however, applies when such ML estimates (i.e. the coefficient $\beta$ ) are equal to one. Within the context of the simulation, this occurs at initial firm sizes that are relatively small (but not too small), ranging from $n_{0}=75$ to $n_{0}=95$.

3.8 When observed in various social phenomena, a unifying explanation behind Zipf's law is not clear. When graphing the relationship between word frequencies with respect to their size, Zipf (1949) proposed the principle of least effort, i.e. speakers and hearers of a given language will not work any harder than necessary to reach an understanding of that language. ZipfâĂŹs law has also been found in the rank-size distribution of webpages, explained by website growth rates, caching and networks (Adamic \& Huberman 2002). With regard to cities, Simon (1955) found that those in the upper tail follow similar growth processes. Furthermore, shocks (such as regional shocks or municipal policy shocks) stop declining with size, after a certain size (Gabaix 1999. Thus, Zipf's law arises through the adjustment of organizational patterns through a system of positive and negative feedback loops (Stanley et al. 1996).

3.9 Axtell 2001) found that, with regard to firm sizes, the shape of such power law distributions, such as Zipf's law, is independent on how size is defined. Thus, following from Stanley et al. (1996) and Brown \& Medoff (1989), there are limits on firm dynamics. Firm growth rates follow a Laplace distribution, and the standard deviation in those growth rates decrease with respect to initial firm size according to a power law. Additionally, larger firms pay higher wages for the same job according to yet another power law (Axtell|2001, p. 1820). In the context of the simulation in this paper, these constraints are knowledge. Penrose (1959) found that (given the conditions of equilibrium analysis), there must be something to prevent the indefinite expansion of the firm.

3.10 Penrose 1959) identifies two constraints. The first of these is the ability to manage complexity. At some point, a firm may become "too big to be efficiently handled" (Penrose 1959, p. 18). In the context of our simulation, the Schumpeterian multiplier accounts for both the incentive for an entrepreneur to leave an incumbent firm (and establish a new one) as well as the degree to which a certain new idea fits in with the incumbent firm. Managing an ever increasing complexity of knowledge becomes burdensome for all firms at some point (even though larger firms may have a relatively easier constraint due to their larger multipliers). Penrose's second constraint is that of knowledge itself. A firm can only grow as fast as its own knowledge, both within and beyond the firm. In the simulation, actors have a degree of 'vision' which they obtain through a system of constrained inheritance. Furthermore, new ideas are only ever a product of existing ideas. Thus, as knowledge is a product of an evolutionary process, a firm is constrained by that evolutionary process. This may serve as an explanation of Zipf's law in our simulation.

3.11 Table 3 shows that the coefficient of Zipf's distribution is not linear with respect to initial firm size. Thus, in the 
context of the model, Zipf's law is an emergent phenomena that comes about when initial firm size is within a subset of initial conditions. This emergent property is when the initial firm size gives rise to a given number of firms via set of inherited parameters. Bridging this observation into the real world, we can make two points. First, there is perhaps an 'ideal' de novo firm size, measured in terms of its knowledge set, which is sustainable. Second, and more fundamentally, the constraints brought about by human cognition constrict the initial conditions available. These initial conditions, which in turn influence future firm sizes through path dependence, are based upon actors' understanding of the knowledge landscape around them. Physical and social technologies that change this level of cognitive reach (and hence alter the equation set out in 5, may in turn alter the conditions in which Zipf's law emerges. Indeed, Axtell (2001) found that although Zipf's law remained constant throughout the years of study, the average size of firms did not. Technology alone may therefore have an impact on firm size, but not firm-size distribution, which is dependent on the cognitive abilities of actors.

\section{Conclusion}

4.1 The computational simulation in this paper, although artificial in the strictest sense, may have real-world implications for analyzing the comparative statics of various geographical regions. In other words, can we explain technological diversity between regions by the size of initial firm? Klepper (2007) found that, for the automobile cluster of Detroit, the geographic concentration of industry is the result of four early successful entrants, and subsequent spin-offs were a function of disagreements with the parent firms' existing R\& D strategies. Thus, given the assumptions and mechanisms of the above simulation, predictions of regional evolution could be made based on the region's current market structure. Regions with few, larger firms could have a significantly different path-dependent fate compared with a region of many smaller firms (but within the same industry). If units of knowledge (or kens) can proxy for firm size, this model has replicated the empirical regularities of previous studies. Further research could explore this question by expanding the model to include multiple (and industrially dissimilar) firms as an initial condition.

4.2 The findings of this paper add to the argument put forward by Klepper (2009), in that the superior performance of firms in a geographical area is due to the higher quality of spin-offs and not any specific geographic attributes. This paper does not address geographic distance, and assumes that all firms are located within the same geographic area. The paper does, however, highlight the role of cognitive distance in its role in the performance of firms. The performance of spin-offs is a function of the cognitive properties that pertain to them. Furthermore, inexperienced firms that choose to locate within a cluster tend to perform better than those who do not. Although this paper does not address these type of firms, it may be argued that this is a result of knowledge spillovers. However, this would also mean that such inexperienced de novo firms would have a disadvantage compared to spin-offs in a region as they lack the advantage of preferential knowledge of the parent firmâÁŹs idea set. This ties-in with Andersson \& Klepper (2013), who found that pulled spin-offs in the same sector as their parents have a lower hazard rate of survival compared to other types of spin-offs.

4.3 The model has potential to be extended in a number of ways. One of these could be the 'death' of firms. However, considering the possibility of takeovers and sell-offs, the patents and ideas present in a defunct firm would be transferred to a new one, and this would effectively change the dynamics of the cognitive understanding of various technology sets on the firm-level. Another issue is the potential effects that result from closed firms. If a firm dies, its employees may have to become 'forced entrepreneurs', effectively rescuing their specialized skills by establishing a firm similar to the defunct one. This mechanism is not captured by this paper's interpretation of entrepreneurship and the cognitive consequences are likely to be similar to the merger and acquisition scenario.

4.4 This paper described the effects of initial firm size on industrial clustering patterns using a highly simplified model of technical cognition. An initially large firm gives rise to fewer, but larger, spin-offs when measured in terms of their produced knowledge set. Conversely, smaller initial firms, over a certain threshold, tend to spawn fewer firms and of smaller size. If firm size, measured in terms of the number of generated ideas, could proxy for profits, employee size or market share, the model confirms empirical regularities. Specific patterns of industrial clustering are a result of the characteristics of entrepreneurs themselves, modelled through the differences in their cognitive reach, and these differences are endowed through a process of inheritance.

4.5 In sum, this paper has modelled clustering patterns via a process of recombinant innovation. The difficultly in measuring or defining a firm's set of ideas is rectified due to the model's level of abstraction. Altering and extending the rules of this model may hopefully provide a basis for future work in evolutionary economic geography. 


\section{Notes}

${ }^{1}$ Specifically, this paper examines pulled spin-offs, in which an employee leaves an incumbent firm to establish a new venture, while the incumbent firm may or may not continue to operate.

2 Sørensen (2007); Elfenbein et al. 2010); Sørensen \& Phillips 2011) find that the larger the spin-off's parent, the worse the spin-off's financial performance and hence the shorter the firm's longevity.

${ }^{3}$ Other factors are of course fundamental. These can include those that are external to firms and their spinoffs (i.e. industry structure and profitability, access to credit and availability of skills) as well as internal (i.e. career paths, incentive mechanisms and organizational identity). Indeed, Schumpeter (1934) stressed the role of credit in the business cycle and as a critical conduit for the entrepreneurial process. These factors are empirical facts. After empirically controlling for these factors, authors such as Klepper (2007, 2009, 2010) and Klepper \& Sleeper (2005) found that what is left over is an implied inheritance process of knowledge, skills and routines. The simulation in this paper aims to fill that void.

${ }^{4}$ It should be noted, however, that the benefits of the printing press were only felt on the scale of cities. Dittmar 2011), using aggregate productivity and per capita income as measures of surplus, found that the gains from books were initially only found in printing cities. Only upon the introduction of mass-transportation techniques centuries later were the benefits felt world-wide. This patter was similar to the rise of the use of computers and the Internet, the mass benefits of which were only felt until the mid-1990's.

${ }^{5} \mathrm{Ken}$ is the Scots English word for "to know, perceive or understand", "a piece of knowledge" or "the scope or bounds of one's understanding" (Dictionary of the Scots Language 2016). This is not to be confused with the so-called 'kene' as defined by Gilbert (1997), a portmanteau of 'knowledge' and 'gene', which is defined as the entire knowledge base of a firm.

${ }^{6}$ In this paper, we frequently use biological analogies to describe certain abstract concepts. However, one needs to bear in mind that such analogies do not (and should not) extend to social systems as a whole. Social systems do not display the same properties as biological ones. This includes the presence of multiple membership (i.e. being part of many organizations at the same time), the lack of what may be defined as a 'boundary' (see Williamson 1975, 1985, Pfeffer \& Salancik 1978 Ashkenas et al. 1995; Jarillo 1993), and the lack of a clear definition of what a role (or competency) is within an organization. Biggiero (2001) gives a clear warning of the fallacy in describing firms using purely biological concepts as this is misleading for understanding social systems.

${ }^{7}$ Cognition is a three-dimensional vector comprised of all possible phenotypes, i.e. $D=\left[p_{1}, p_{2}, p_{3}\right]^{T}$

'Biggiero (2001), building on work by Williamson (1975, 1985); Pfeffer \& Salancik 1978); Ashkenas et al., (1995); Jarillo (1993) showed that firms (either composed of such actors, or as the actors themselves) are not closed systems as they are constantly searching for efficient resources, and these resources may include knowledge.

${ }^{9}$ The cognitive reach may be illustrated using the distribution's quantile function, where $u$ is a random draw of any real number less than 1, i.e. $F^{1}(u)=r \ln [1-\ln (1-u)], u \in[0,1)$

${ }^{10}$ This is modelled on Hirsch (1992), who showed that, given groups of neurons that are physically similar but with bell-shaped distributed activation thresholds, the resulting network group of neurons will have a sigmoidal distribution of activation thresholds.

${ }^{11}$ This paper takes the moderate constructivist epistemology (Biggiero|2012) that knowledge may be both reified meta-information, i.e. an 'object', as well as an emergent property of a network. While the former may be 'possession', the latter is viewed as 'practice'. In the case of the latter, and in the context of the current model, an unseen and undefined network is implied. Imagine the cognitive space as a geographical one, containing a series of road networks. Firms (or kens) that are cognitively proximate to one another are connected via shorter roads. However, that does not necessarily mean that two firms (or kens) can easily connect. That depends on the effectiveness of transportation (or, to break away from this geographic analogy, their cognitive reach).

${ }^{12} \mathrm{~A}$ description of these first appeared in English by Kondratieff (1979), although Kondratieff's original concept originated some decades earlier.

${ }^{13}$ Author's own interpretation, using Kondratieff (1979) and Schumpeter (1943).

${ }^{14}$ There are no borders within the cognitive space, and firms do not imply borders either. Multiple membership of organizations may exist everywhere and nowhere. There is nothing that implies it does not, and there is nothing to imply that it does. Moreover, an idea-generating institution does not have to be a profit-producing organization but also does not even have to be an organization. We can view this model in terms of, for example, 
music genres coupled with mathematics, even though music theory has no axiomatic foundation in modern mathematics. Thus, it is important to use an abstract mindset when thinking about this model. For a less abstract approach that uses real data in a knowledge space, see Biggiero \& Basevi 2016) and Biggiero \& Angelini 2015) for research that deals explicitly with R\& D collaboration networks.

${ }^{15}$ This constant may be thought of as a 'damper' that reflects the lack of competition pressures and the de novo nature of the employees, i.e. the lack of experience from previous firms. The significance of this constant becomes important during the model's run as it increases the probability of the first firm producing a spawn.

${ }^{16}$ Again, for simplicity, we illustrate using a two-dimensional cognitive space

${ }^{17}$ Both $1 / r$ and $S$ follow the same principles, as seen in Equations 5 and 7 . However, unlike 5 , there is no 'damper' $a$. We can assume that cognitive reach and the Schumpeterian multiplier behave differently in this respect. While we can envisage a lack of experience (due to being a de novo firm) may impact the search behaviour of actors, there is little reason to suspect that there would be a similar damper on the incentives of entrepreneurs (as well as the incentives of incumbent firms). This is why $a$ only appears in Equation 5 , and not Equation 7 .

${ }^{18}$ Consider ken $i$, which is part of the knowledge set of a spin-off firm. Before the crossover and mutation process, ken $i$ links up with another ken that may belong to one of two sets. The first set is comprised of all kens in the spin-off's parent firm. The second set is comprised of all kens in $i$ 's search area as dictated by Equation 2 . In any given discrete time period, ken i may link up with kens in either set with equal probability.

${ }^{19} \mathrm{~A}$ firm does not inherit the parent firm's knowledge base, but has the means to search it, and only through one of its own kens. There is an implicit assumption that spin-offs are connected to their parent firms via a network of sorts. Compared with other firms, there is a better sense of familiarity with the parent firm. Maintained connections, as well as past immersive experience with the parent firm provides this familiarity. The kens of the parent firm act as 'library' that the spin-off's kens may use.

${ }^{20}$ This is an expansion on the work by Nelson \& Winter 1982

${ }^{21}$ This snapshot gives the appearance that firms take the form of 'islands' that occupy the sea of the cognitive space. It is important to note that the model gives rise to the appearance of islands, depending on initial parameters. There is, theoretically, nothing preventing firms from 'overlapping' with one another to share zones in the cognitive space. Indeed, this is one potential outcome.

${ }^{22}$ i.e., $\log R=\alpha+\beta \log n$, where $R$ is the firm's rank and $n$ is its size.

\section{References}

Adamic, L. A. \& Huberman, B. A. (2002). Zipf's law and the internet. Glottometrics, 3(1), 143-150

Agarwal, R., Echambadi, R., Franco, A. M. \& Sarkar, M. B. (2004). Knowledge transfer through inheritance: Spinout generation, development, and survival. Academy of Management Journal, 47(4), 501-522

Aghion, P., Bloom, N., Blundell, R., Griffith, R. \& Howitt, P. (2005). Competition and innovation: An inverted-U relationship. The Quarterly Journal of Economics, 120(2), 701-728

Ahuja, G. \& Morris Lampert, C. (2001). Entrepreneurship in the large corporation: A longitudinal study of how established firms create breakthrough inventions. Strategic Management Journal, 22(6-7), 521-543

Amaral, L. A. N., Buldyrev, S. V., Havlin, S., Leschhorn, H., Maass, P., Salinger, M. A., Stanley, H. E. \& Stanley, M. H. R. (1997). Scaling behavior in economics: I. Empirical results for company growth. Journal de Physique I, $7(4), 621-633$

Amaral, L. A. N., Buldyrev, S. V., Havlin, S., Salinger, M. A. \& Stanley, H. E. (1998). Power law scaling for a system of interacting units with complex internal structure. Physical Review Letters, 80(7), 1385

Andersson, M. \& Klepper, S. (2013). Characteristics and performance of new firms and spinoffs in Sweden. Industrial and Corporate Change, 22(1), 245-280

Antonelli, C. (2010). Pecuniary externalities and the localized generation of technological knowledge. In The Handbook of Evolutionary Economic Geography, (pp. 162-181). Cheltenham: Elgar

Arthur, W. B. (1989). Competing technologies, increasing returns, and lock-in by historical events. The Economic Journal, 99(394), 116-131 
Arthur, W. B. (2005). The logic of invention. Santa Fe Institute Working Paper, 2005-12-045

Arts, S. \& Veugelers, R. (2014). Technology familiarity, recombinant novelty, and breakthrough invention. Industrial and Corporate Change, 24(6), 1215-1246

Ashkenas, R., Ulrich, D., Jick, T. \& Kerr, S. (1995). The Boundaryless Organization. San Francisco, CA: Jossey-Bass

Axtell, R. L. (2001). Zipf distribution of US firm sizes. Science, 293(5536), 1818-1820

Biggiero, L. (2001). Are firms autopoietic systems? In Sociocybernetics: Complexity, Autopoiesis, and Observation of Social Systems, (pp. 125-140). Westport, CT: Greenwood

Biggiero, L. (2012). Practice vs. possession: Epistemological implications on the nature of organizational knowledge and cognition. In Research Methodologies, Innovations and Philosophies in Software Systems Engineering and Information Systems, (pp. 82-105). Hershey, PA: IGI Global

Biggiero, L. \& Angelini, P. P. (2015). Hunting scale-free properties in r\&d collaboration networks: Selforganization, power-law and policy issues in the European aerospace research area. Technological Forecasting and Social Change, 94, 21-43

Biggiero, L. \& Basevi, M. (2016). Knowledge creation and transfer within industrial networks practices: The role of absorptive capacity and direct centrality. In Relational Methodologies and Epistemology in Economics and Management Sciences, (pp. 313-347). Hershey, PA: IGI Global

Biggiero, L. \& Valente, M. (2016). The role of knowledge heterogeneity in industrial clusters knowledge dynamics: An application of the boolean network simulation modeling. In Relational Methodologies and Epistemology in Economics and Management Sciences, (pp. 257-282). Hershey, PA: IGI Global

Brittain, J. \& Freeman, J. (1986). Entrepreneurship in the semiconductor industry. Annual meeting of the Academy of Management, Dallas

Brown, C. \& Medoff, J. (1989). The employer size-wage effect. Journal of Political Economy, 97(5), 1027-1059

Burton, M. D., Sørensen, J. B. \& Beckman, C. M. (2002). Coming from good stock: Career histories and new venture formation. In Social Structure and Organizations Revisited, (pp. 229-262). Bingley: Emerald

Cassiman, B. \& Ueda, M. (2006). Optimal project rejection and new firm start-ups. Management Science, 52(2), 262-275

Christensen, C. M. (1993). The rigid disk drive industry: A history of commercial and technological turbulence. Business History Review, 67(4), 531-588

Christensen, C. M. \& Bower, J. L. (1996). Customer power, strategic investment, and the failure of leading firms. Strategic Management Journal, (pp. 197-218)

Dahlman, C. J., Ross-Larson, B. \& Westphal, L. E. (1987). Managing technological development: Lessons from the newly industrializing countries. World Development, 15(6), 759-775

David, P. A. (1985). Clio and the economics of QWERTY. American Economic Review, 75(2), 332-337

Dictionary of the Scots Language (2016). Scottish National Dictionary (1700-) listings for 'Ken'. Http://www.dsl.ac.uk/entry/snd/ken. Archived at: http://www.webcitation.org/6m0gSu5Q9

Dittmar, J. E. (2011). Information technology and economic change: The impact of the printing press. The Quarterly Journal of Economics, 126(3), 1133-1172

Elfenbein, D. W., Hamilton, B. H. \& Zenger, T. R. (2010). The small firm effect and the entrepreneurial spawning of scientists and engineers. Management Science, 56(4), 659-681

Eriksson, T. \& Kuhn, J. M. (2006). Firm spin-offs in Denmark 1981-2000 - Patterns of entry and exit. International Journal of Industrial Organization, 24(5), 1021-1040

Franco, A. M. \& Filson, D. (2000). Knowledge diffusion through employee mobility. Tech. rep., Claremont Colleges Working Papers in Economics 
Frenken, K. \& Boschma, R. A. (2007). A theoretical framework for evolutionary economic geography: Industrial dynamics and urban growth as a branching process. Journal of Economic Geography, 7(5), 635-649

Gabaix, X. (1999). Zipf's law for cities: An explanation. The Quarterly Journal of Economics, 114(3), 739-767

Garvin, D. A. (1983). Spin-offs and the new firm formation process. California Management Review, 25(2), 3-20

Gilbert, N. (1997). A simulation of the structure of academic science. Sociological Research Online, 2(2)

Gompers, P., Lerner, J. \& Scharfstein, D. (2005). Entrepreneurial spawning: Public corporations and the genesis of new ventures, 1986 to 1999. The Journal of Finance, 60(2), 577-614

Henderson, R. M. \& Clark, K. B. (1990). Architectural innovation: The reconfiguration of existing product technologies and the failure of established firms. Administrative Science Quarterly, (pp. 9-30)

Hirsch, M. W. (1992). Dynamics and neural networks. In Research Methodologies, Innovations and Philosophies in Software Systems Engineering and Information Systems, (pp. 31-51). London: World Scientific

Hvide, H. K. (2009). The quality of entrepreneurs. The Economic Journal, 119(539), 1010-1035

Jacobs, J. (1969). The Economy of Cities. New York, NY: Random House

Jarillo, J. C. (1993). Strategic Networks: Creating the Borderless Organization. Butterworth: Heinemann

Kauffman, S. A. (1993). The Origins of Order: Self-Organization and Selection in Evolution. Oxford: Oxford University Press

Kauffman, S. A. (1996). At Home in the Universe: The Search for the Laws of Self-Organization and Complexity. Oxford: Oxford University Press

Kauffman, S. A. (2000). Investigations. Oxford: Oxford University Press

Kim, L. (1980). Stages of development of industrial technology in a developing country: A model. Research Policy, 9(3), 254-277

Klepper, S. (2007). Disagreements, spinoffs, and the evolution of Detroit as the capital of the U.S. automobile industry. Management Science, 53(4), 616-631

Klepper, S. (2009). Spinoffs: A review and synthesis. European Management Review, 6(3), 159-171

Klepper, S. (2010). The origin and growth of industry clusters: The making of Silicon Valley and Detroit. Journal of Urban Economics, 67(1), 15-32

Klepper, S. (2011). Nano-economics, spinoffs, and the wealth of regions. Small Business Economics, $37(2), 141$

Klepper, S. \& Sleeper, S. (2005). Entry by spinoffs. Management Science, 51(8), 1291-1306

Koestler, A. (1964). The Act of Creation. London: Hutchinson

Kondratieff, N. D. (1979). The long waves in economic life. Review (Fernand Braudel Center), 2(4), 519-562

Lall, S. (1992). Technological capabilities and industrialization. World Development, 20(2), 165-186

Marshall, A. (1920). Principles of Economics. London: Macmillan

McKendrick, D. G., Wade, J. B. \& Jaffee, J. (2009). A good riddance? Spin-offs and the technological performance of parent firms. Organization Science, 20(6), 979-992

Nelson, R. R. \& Winter, S. G. (1982). An Evolutionary Theory of Economic Change. Cambridge, MA: Harvard University Press

Nooteboom, B., Van Haverbeke, W., Duysters, G., Gilsing, V. \& Van den Oord, A. (2007). Optimal cognitive distance and absorptive capacity. Research Policy, 36(7), 1016-1034

Patrucco, P. P. (2009). Collective knowledge production costs and the dynamics of technological systems. Economics of Innovation and New Technology, 18(3), 295-310

Penrose, E. T. (1959). The Theory of the Growth of the Firm. Oxford: Oxford University Press 
Pfeffer, J. \& Salancik, G. R. (1978). The External Control of Organizations: A Resource Dependence Perspective. New York, NY: Harper \& Row

Phillips, D. J. (2002). A genealogical approach to organizational life chances: The parent-progeny transfer among Silicon Valley law firms, 1946-1996. Administrative Science Quarterly, 47(3), 474-506

Rosenkopf, L. \& Nerkar, A. (2001). Beyond local search: Boundary-spanning, exploration, and impact in the optical disk industry. Strategic Management Journal, 22(4), 287-306

Schumpeter, J. A. (1934). The Theory of Economic Development. Cambirdge, MA: Harvard University Press

Schumpeter, J. A. (1943). Capitalism, Socialism and Democracy. London: Allen Unwin

Simon, H. A. (1955). On a class of skew distribution functions. Biometrika, 42(3/4), 425-440

Solé, R. V., Amor, D. R. \& Valverde, S. (2014). On singularities in combination-driven models of technological innovation. Santa Fe Institute Working Papers, 2014-08-025

Sørensen, J. B. (2007). Bureaucracy and entrepreneurship: Workplace effects on entrepreneurial entry. Administrative Science Quarterly, 52(3), 387-412

Sørensen, J. B. \& Phillips, D. J. (2011). Competence and commitment: Employer size and entrepreneurial endurance. Industrial and Corporate Change, 20(5), 1277-1304

Stanley, M. H. R., Amaral, L. A. N., Buldyrev, S. V., Havlin, S., Leschhorn, H., Maass, P., Salinger, M. A. \& Stanley, H. E. (1996). Scaling behaviour in the growth of companies. Nature, 379(6568), 804-806

Tåg, J., Åstebro, T. \& Thompson, P. (2013). Hierarchies, the small firm effect, and entrepreneurship: Evidence from swedish microdata. IFN - Institute för Näringslivsforskning Working Paper, 954

Wagner, J. (2004). Are young and small firms hothouses for nascent entrepreneurs? Evidence from German micro data. Applied Economics Quarterly, 50(4), 379-391

Williamson, O. E. (1975). Markets and Hierarchies. New York, NY: The Free Press

Williamson, O. E. (1985). The Economic Institutions of Capitalism. New York, NY: The Free Press

Zipf, G. (1949). Human Behavior and the Principle of Least Effort. Cambridge, MA: Addison-Wesley 